\title{
Prospects for chemical trapping for solar energy*
}

\author{
BALU VENKATARAMAN \\ Tata Institute of Fundamental Rescarch, Homi Bhabha Road, Bombay 400005 , India
}

Thank you for the honour given me to deliver this keynote address at the first workshop held after the launch of the project on "Chemical routes for trapping solar energy". In March 1983 many of us met at a workshop sponsored by the Tata Energy Research Institute (TERI) and it took us almost three years for implementing, that too only partly, the recommendations of the workshop. In 1984 a Task Force under the chairmanship of Mr K S Hinge of Tata Oil Mills was appointed by TERI; this in turn appointed three subcommittees to generate coordinated projects in the area of photoelectrochemistry, photocatalysis and biomimetism and photosynthesis. These subcommittees met several times and by April 1985 had generated a work plan for each area. In April 1985 the Department of Nonconventional Energy Sources (DNES) joined hands with TERI and a new Task Force was appointed under the chairmanship of Prof. S Ramaseshan. Finally by April 1986 many projects in the area of photoelectrochemistry and two projects in the area of biomimetism and photosynthesis were sanctioned by DNES. These projects involve 15 institutions and 25 senior research scientists. The task and objectives are outlined below:

(i) To achieve efficiencies in liquid junction solar cells comparable with that reported from outside India and to determine the conditions under which these can be obtained. (Most of the claims cannot be verified since experimental conditions are being maintained as close secrets.)

(ii) To identify new electrode materials, electrolytes and methods of stabilizing electrodes.

(iii) To develop a rechargeable solar cell.

(iv) To study from the basic science angle the factors that determine the efficiency of a PEC device.

(v) To construct and test artificial models for mimicking photosynthesis to gather and utilize solar energy efficiently.

(vi) To understand hydrogen production by algae, bacteria and chloroplasts and to develop hydrogenases with greater stability. The Task Force has not yet sanctioned any project in the area of photocatalysis.

The author would like to place on record the pivotal role played by Prof. Ramaseshan as the Chairman of the Task Force, in having many projects initiated. He has recently relinquished the chairmanship and Prof. A K Barua, Director of the Indian Association for the Cultivation of Science has agreed to be the Chairman of the Task Force. We thank and welcome him to join our effort, which is unique in the Indian scene in the sense that it is perhaps the first time that a national coordinated effort is being made in a major frontier area of research.

*Text of the keynote address delivered at the National Workshop on Energy Resources through Photoelectrochemical Routes, May 1987. 
Some of us consider this as an area of future potential and the strides made internationally during the last six years are very impressive. If we consider the photoelectrochemical cell alone the highlights reported in some of the international conferences on photochemical conversion and storage of solar energy (IPS 3, 5 and 6) are good indicators of the rapid advances in this area:

\begin{tabular}{|c|c|c|c|}
\hline & $\begin{array}{c}\text { III IPS } \\
\text { Boulder } \\
1980\end{array}$ & $\begin{array}{c}\text { V IPS } \\
\text { Osaka } \\
1984\end{array}$ & $\begin{array}{c}\text { VI IPS } \\
\text { Paris } \\
1986\end{array}$ \\
\hline $\begin{array}{l}\text { Liquid junction PV } \\
\text { cells }\end{array}$ & $\begin{array}{l}\text { (a) Crystalline CdS, } \\
\mathrm{CdSe}, \mathrm{CdTe} \text { and } \mathrm{CdSe}_{\alpha} \\
\mathrm{Te}_{\alpha-1} \text { with } \mathrm{S}_{2}^{-}, \mathrm{Se}_{2}^{-} \\
\text {Poor efficiency and stabi- } \\
\text { lity } \\
\text { (b) Thin films of } \mathrm{CdS} \text { on } \\
\mathrm{Ti} \text { with } 1 \mathrm{M} \mathrm{NaOH} \\
+1 \mathrm{M} \mathrm{Na}_{2} \mathrm{~S}+1 \mathrm{M} \mathrm{S} \sim \\
3 \% \text { efficiency }\end{array}$ & $\begin{array}{l}\text { (b) Single crystal } \\
\mathrm{CdSe}_{0.65} \mathrm{Te}_{0.35} \text { with Cs- } \\
\text { sulfide electrolyte } \sim 12 \% \\
\text { high stability }\end{array}$ & $\begin{array}{l}\text { (a) Single crystal } n \text {-WSe } \\
\text { in } 0.05 \mathrm{M} I_{2}+2 \mathrm{M} \mathrm{KI} \\
\text { aqueous }(\sim 10 \%) \\
\text { (b) Single crystal GaAs } \\
+\mathrm{SnO}_{2} \text { electrodes with } \\
0.2 \mathrm{M} \text { dimethyl ferrocene/ } \\
0.2 \mathrm{M} \text { dimethyl ferro- } \\
\text { cenium in } 1 \mathrm{M} \mathrm{KClO} \\
\sim 10 \% \text { Stable at least } \\
\text { for } 20 \text { days } \\
\text { (c) CdTe with (S } \\
\left.\mathrm{Se}^{-}\right) \text {and (S } \mathrm{S}_{x}^{-} \\
\left.\text {or } \mathrm{Te}_{-}^{-}(5 \text { to } 10 \%)\right)\end{array}$ \\
\hline Photoelectrosynthesis & $\begin{array}{l}\text { Maximum efficiency re- } \\
\text { ported for water splitting } \\
-1 \% \text { and less than that } \\
\text { for } \mathrm{CO}_{2} \text { and } \mathrm{N}_{2} \text { fixation }\end{array}$ & $\begin{array}{l}\text { (a) } \mathrm{H}_{2} \text { production with } \\
\text { passivated surface of p- } \\
\text { InP having and sub } \\
\text { diameter } 100 \text { nm hydro- } \\
\text { gen saturated } \mathrm{Rh} \text { islands } \\
-12 \% \\
\text { (b) } \mathrm{Pt} \text { coated p-n junc- } \\
\text { tion } \mathrm{Si} \text { photoanode, a Pt } \\
\text { cathode aqueous HI } \mathrm{HI} \\
\text { electrolyte } \mathrm{H}_{2} \text { with } 8 \% \\
\text { (c) } \mathrm{CO}_{2} \text { and } \mathrm{N}_{2} \text { fixation } \\
\text { being attempted }\end{array}$ & $\begin{array}{l}\text { (a) } \mathrm{H}_{2} \text { production from } \\
\text { aqueous } \mathrm{HI} \text { with } p \text {-Si/n- } \\
\mathrm{Si}_{\text {, treated with a metal }} \\
\text { ( } \mathrm{Pt}, \mathrm{W} \text { or } \mathrm{Mo} \text { ) coupling } \\
\sim 10 \% \\
\text { (b) } \mathrm{CO}_{2} \text { and } \mathrm{N}_{2} \text { fixation } \\
\text { attempted. }\end{array}$ \\
\hline
\end{tabular}

What I shall do is not to discuss in any detail the different photochemical approaches for trapping solar energy. Many of my colleagues will do this in their updates and they will educate us as to where we stand in each area. What I shall present here is

(a) to discuss in general the challenges and competitions facing this area of research, (b) to mention a few achievements in the recent past--as announced in the VI International Conference in Paris in August 1986.

(c) to suggest a strategy for research in this area.

\section{General remarks}

I shall first make a few general remarks. The sun has a surface temperature of $6000 \mathrm{~K}$ and emits a tremendous amount of energy $\left(24 \times 10^{26}\right.$ joules/second in the form of 
electromagnetic radiation). What reaches us after a travel of 149 million $\mathrm{km}$ in 8 minutes is 1360 watts $/ \mathrm{m}^{2}$ (on a surface perpendicular to the solar beam) outside our atmosphere. At mid-day with normal sunshine, the surface of the earth receives about $1 \mathrm{~kW} / \mathrm{m}^{2}$ and the distribution of energy in the various wavelengths of the electromagnetic radiation is shown in figure 1.

The IR photons $(\lambda>800 \mathrm{~nm})$ can be easily absorbed with increase in the temperature of the material. Sun-drying is an age-old practice (including dehydrating foods for preservation, etc). These thermal devices are well known and are being applied for solar cooking, solar water heating, solar furnaces, etc.

What we are concerned with is the use of photons $(\lambda<800 \mathrm{~nm})$ to provide the energy to cause chemical changes (chemical changes which need energy since they are uphill). These changes could result in (i) production of energy-rich compounds known as fuels and (ii) separation of charges as in a silicon photo-voltaic cell for generating electricity. The formation of a fuel leading to energy storage is depicted in figure 2 .

The general problems associated with the utilization of solar energy through chemical routes are:

(i) The diffusive nature of solar energy-we can compare the land needs for a $100 \mathrm{MW}$ power station based on coal or on solar energy. The coal needed daily (2400 metric tons) occupies a volume of $1850 \mathrm{~m}^{3}$ and can be stored in an area of $185 \mathrm{~m}^{2}(0.05$ acres $)$ if stacked to a height of $10 \mathrm{~m}$. To obtain the solar energy needed per day we need a collection area of $34 \times 10^{4} \mathrm{~m}^{2}(\sim 84$ acres) assuming that we can collect and store all the energy needed for 24 hours during day time at $7 \mathrm{kWh} / \mathrm{day} /$ $\mathrm{m}^{2}$.

(ii) Loss of efficiency due to back reactions-since the solar photons are trapped by driving reactions uphill the tendency for back reactions always exist. The two commonly used principles to minimize losses are (i) removal of the products formed from the site of the reaction as in the case of photoelectrochemical cells, where charges are separated instantaneously, (ii) the existence of an energy harrier for the reverse reaction (see figure 2 ) as in fuels. Both the methods necessitate a decrease in the overall efficiency of conversion and the ideal maximum efficiency (solar engineering efficiency) is calculated to be $39 \%$.

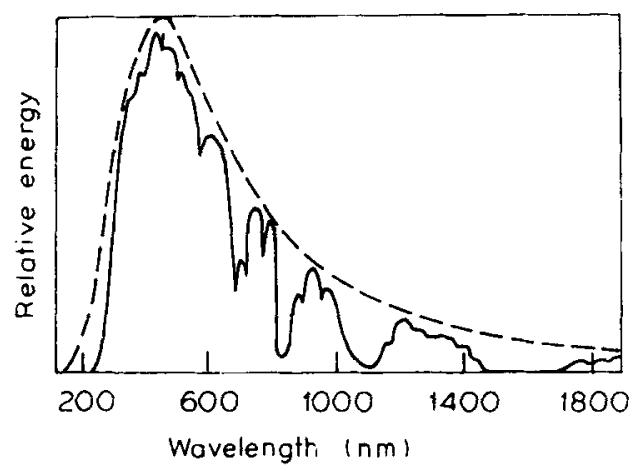

Figure 1. Energy distribution of solar radiation reaching the earth's surface (solid ourve) and earth's atmosphere (dashed curve). Dips in solid curve are due to absorption by molecules in atmosphere. 


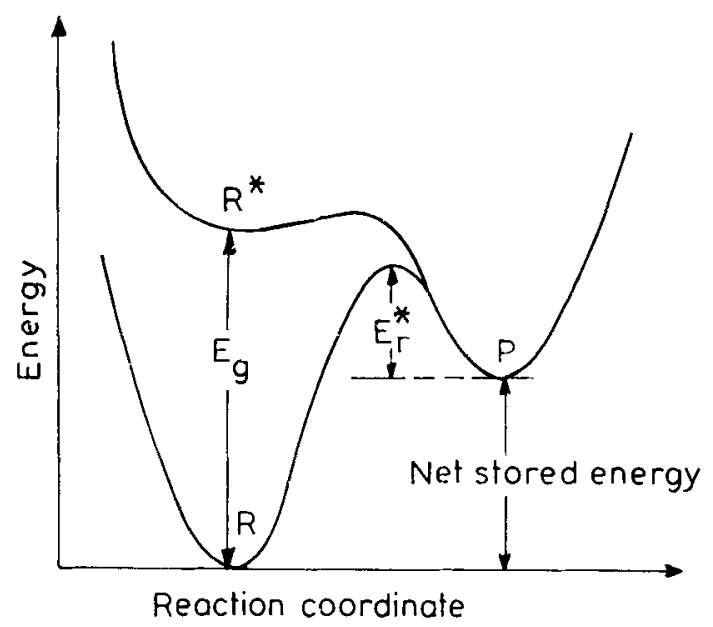

Figure 2. Energy profile of a general photochemical reaction with $\Delta G>0$ (endergonic). $E_{q}$ Is the minimum energy gap between the lowest vibrational levels of the excited state $R^{*}$ and the ground statc $R ; E_{r}^{*}$ is the activation energy for the back reaction $P \rightarrow R$. $P$, the fuel formed by this reaction is prevented from transforming to $R$ by the barrier $E_{r}^{*}$. The energy stored (in the fuel) is $E_{4}-E_{r}^{*}$

\section{Challenges faced}

The major challenge to the chemical routes arises from the great advances made in the area of solid state photovoltaic cells. The advent of amorphous silicon cells has made it possible to consider the establishment of power stations with this technology. The trend in decreasing costs of silicon cells does force us to examine time and again the viability of a liquid junction photoelectrochemical (PEC) cell.

While the process of fabrication of a PEC cell is expected to be simpler and hence cheaper, and high efficiencies have already been indicated, it is not at all clear as yet whether one can achieve the stability required for commercial viability. This is perhaps the most challenging problem.

One of the great advantages of the chemical routes is the inherent possibility of storing energy in the same structure. In fact this perhaps can be the real selling point of a PEC device. The possibility of a solar-rechargeable-PEC device replacing the present solid state PV cell-storage battery combination in our villages, does not seem to be remote. Our efforts will have to be directed towards this goal.

A solar cell has the greatest attraction towards applications in remote places and in defence. However, even for remote applications, the recent discovery of high temperature superconductors is expected to revolutionize power transmission technology and hence decrease the remoteness of far-flung places. What I am trying to emphasize is that the research and development effort should not be limited only to electricity generation. All aspects of chemical trapping should be investigated.

Photoelectrochemical synthesis of value-added products is yet another area where high efficiencies have been indicated. Photocatalysis, especially with particulates, has emerged as an area of great potentialities.

Some highlights of the Paris (IPS 6) Conference, 1986

(i) In discussing the role of charge separation to minimize back reactions, M Gractzel 
(Switzerland) reported that with Fe-doped $\mathrm{TiO}_{2}$ particulates, he has been able to achieve charge separation for hours.

(ii) Dr Micic (Yugoslavia) and Dr Nozik (USA) studied colloids of extremely small particle size (2-3 nm)-CdS, BiS, $\mathrm{Bi}_{2} \mathrm{~S}_{3}, \mathrm{SnSe}, \mathrm{HgSe}, \mathrm{PbSe}, \mathrm{CdSe}$ and $\mathrm{HgI}_{2}$. They have observed size quantization effects and changes in optical properties. The effective redox potential is greatly enhanced such that certain reactions, which fail to occur in bulk, are found to take place with ultrafine particles.

(iii) Kawai (Japan) reported the application of photocatalysis in pollution abatement. Polluted water with impurities, such as acetic acid. methanol, isopropanol, etc up to about 100 ppm, when exposed to sunlight with $\mathrm{TiO}_{2}$ (anataste) particles coated with platinum, indicated a decrease in the pollutant concentration down to $4 \mathrm{ppm}$. (The semiconductor industry is setting up a pilot plant for assessment.) Adam Heller (USA) indicated similar applications in removal of chlorinated aromatics and polyols.

(iv) M Graetzel (Switzerland) reported the development of graphite electrodes coated with ruthenium dimers for oxidation of water with high efficiency $(\sim 50 \%$ of energy absorbed) and a large turnover $\left(\sim 10^{6}\right)$ indicating great stability.

(v) The composition of the antenna molecules in the photosynthetic apparatus has been established to be 50 to 100 molecules of Chl(b) (ChlC, ChID), carotenes and phycobilins. The first few steps in electron transfer have also been identified:

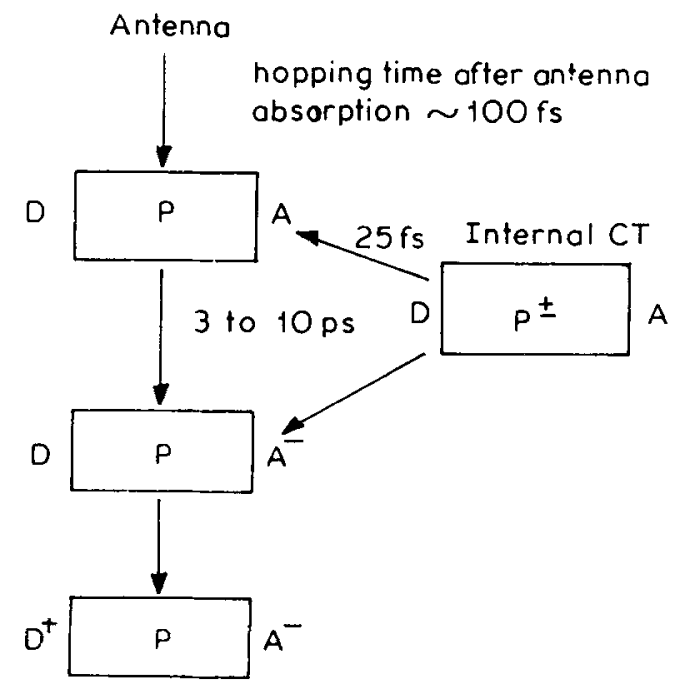

Antenna are avoided in bright sunlight. If antenna are avoided internal charge transfer state, $P^{ \pm}$is also avoided.

\section{Achievements between 1974 and 1986}

The oil crisis in the 70's spurred efforts in this area and the impact of the international venture can be gauged by listing the achievements, not all of which are directly linked to solar energy utilization:

(1) New type of photoactive materials $(>150)$.

(2) Heterogeneous photocatalysis (birth of photoelectrodes). 
(3) Stabilization of photoelectrodes by preferential kinetic control.

(4) Semiconductor surface modification for kinetic control.

(5) Discovery and photoelectric polymerization of new conducting polymers.

(6) Nonthermalized (hot) electron CT.

(7) Unique surface photochemistry.

(8) Photoetching of semiconductors.

(9) Quantization effects in small particles and superlattice elements.

(10) Transparent catalytic metal deposition.

(11) Liquid/solid state junction-non-ideal Fermi level pinning.

(12) Dye sensitization with unit quantum efficiency.

Specifically one can mention the following milestones which are expected to be exploited commercially.

(1) Hydrogen production in PEC cells with efficiencies about $12 \%$ with $\mathrm{p}-\mathrm{In} \mathrm{P} / \mathrm{Pt}$ electrodes and 10 to $13 \%$ with $\mathrm{Si}, \mathrm{GaAs}$ electrodes.

(2) Solar driven pollution abatement.

(3) Photochemical semiconductor processing/etching.

The future

What does the future hold? A list of the areas of research and development, where it is expected that international efforts would lead to an understanding or lead to the development of a process or a commercially viable device, was proposed at the end of the 1986 conference. The list given below is classified as contributions towards developments in science or technological developments:

A. Science

1. Measurement of electron transfer rates (ps)

2. Quantization effects:

$1 \mathrm{dim}=$ superlattices

$2 \operatorname{dim}=$ quantum wires

$3 \mathrm{dim}=$ quantum particles

(optical and electrical props of semiconductors)

3. Novel chemical reactions

4. Hybrid semiconductor-biological system

5. $\mathrm{N}_{2}$ photoreduction

6. $\mathrm{CO}_{2}$ photoreduction

B. Technology

1. PV devices

2. Chemical sensors

3. Solar cell with in-situ storage

4. Passivation of surfaces

5. Pollution abatement

6. Semiconductor device fabrication.

It is obvious from these predictions that we can ill-afford to neglect effort in this area. We have a lesson to learn from the recent Indian developments in the area of high temperature superconductivity. Because of our overall investment during the past decade in the area of materials science, it was possible for our scientists to make 
significant contribution in this highly competitive area, within a short time, following the announcement of the discovery of the phenomenon. Hopefully we would, as a group, make a few outstanding discoveries in the field of solar photochemistry, but more importantly we would have the expertise and infrastructure to adopt any new important findings and even investigate further.

\section{What should our present strategy be?}

From the abstracts presented, it is clear that we have come near the initial goals we had set for ourselves when we embarked on this project. The liquid junction photovoltaic cells fabricated in India have come close to achieving efficiencies reported in literature. We should attempt to improve on them by modifications. It is also necessary to evaluate alternate methods of electrode fabrication and electrode stabilization. With collaboration between various groups many alternatives could be tested and hopefully we would also announce an efficient device with high stability. While photoelectrochemical synthesis of hydrogen should be actively investigated, synthesis of value-added products, especially leading to fixation of carbon and nitrogen should be attempted. It is imperative that, in our country of meagre resources, collaboration and mutual consultation be the key element.

We should soon initiate effort in the area of photocatalysis with special reference to energy saving by finding alternate routes to pollution abatement. The area of photocatalysis in my opinion would be largely justified by its expected contribution to energy conservation rather than energy or fuel production.

Our efforts in the area of biomimetism and photosynthesis, aimed at understanding the elementary steps should utilize the techniques, recently established in our country, for investigation of extremely rapid events.

We have made a beginning and there has been a reasonable progress. We hope that when we meet again at such a national seminar we would have a lot to be proud of. 